\title{
Improving the Appearance of a 3-Coat-1-Bake Coating Film by Minimizing the Shrinkage Difference between the Three Layers
}

\author{
Shuji Yomo *(D) and Kazuyuki Tachi \\ Toyota Central R\&D Labs., Inc., Nagakute 480-1192, Japan; e0397@mosk.tytlabs.co.jp \\ * Correspondence: e1463@mosk.tytlabs.co.jp; Tel.: +81-561-71-7042
}

\footnotetext{
check for updates

Citation: Yomo, S.; Tachi, K. Improving the Appearance of a 3-Coat-1-Bake Coating Film by Minimizing the Shrinkage Difference between the Three Layers. Coatings 2021, 11, 211. https://doi.org/ 10.3390/coatings11020211
}

Academic Editor: Alberto Palmero

Received: 18 January 2021

Accepted: 8 February 2021

Published: 11 February 2021

Publisher's Note: MDPI stays neutral with regard to jurisdictional claims in published maps and institutional affiliations.

Copyright: (c) 2021 by the authors. Licensee MDPI, Basel, Switzerland. This article is an open access article distributed under the terms and conditions of the Creative Commons Attribution (CC BY) license (https:/ / creativecommons.org/licenses/by/ $4.0 /)$.

\begin{abstract}
The 3-coat-1-bake coating system has been widely employed in automobile body painting. This study examined whether the appearance (waviness) of the coating film can be improved by reducing the difference in the shrinkage percentage (by weight) between the primer surfacer and the basecoat and the clearcoat after flow/leveling stops in the clearcoat while baking. To delay the time of flow/leveling stops in the clearcoat $\left(t_{C}\right)$ and to reduce the difference in the shrinkage percentage between the basecoat and clearcoat, solventborne clearcoats were prepared by blocking all or part of the isocyanate group with 3,5-dimethylpyrazole (DMP). $t_{C}$ was measured using the electric-field tweezers system while baking at $140{ }^{\circ} \mathrm{C}$. The respective shrinkage percentages of the primer surfacer, basecoat, and clearcoat $\left(\omega_{S}, \omega_{B}\right.$, and $\omega_{C}$, respectively) were measured after $t_{C} \cdot t_{C}$ increased as the DMP content of the solventborne clearcoat increased. The $\omega_{C}$ value is lower than the $\omega_{S}$ and $\omega_{B}$ values when the DMP content is zero; however, the $\omega_{C}$ value increased when $t_{C}$ increased, and the $\omega_{S}$ and $\omega_{B}$ values decreased as $t_{C}$ increased. Wavescan $\mathrm{Wa}, \mathrm{Wb}, \mathrm{Wc}$, and $\mathrm{Wd}$ decreased (i.e., improved the appearance) as $\left|\omega_{S}-\omega_{B}\right|+\left|\omega_{B}-\omega_{C}\right|$ decreased. We confirmed that reducing the difference in the shrinkage percentage between the primer surfacer, basecoat, and clearcoat after $t_{C}$ is an effective way to improve the appearance.
\end{abstract}

Keywords: appearance; 3-coat-1-bake; clearcoat; wavescan; shrinkage percentage

\section{Introduction}

A variety of coating methods and materials have been introduced for different coating applications for protecting parts and structures against mechanical and chemical damage. A review [1] has been published. An article for coating on flexible substrates [2] and an article for coating to bio-applications [3] are also published.

For automobile bodies, in a conventional manufacturing process, paint is applied to the steel sheets by electrodeposition followed by baking. Then, a primer surfacer is applied and baked, followed by the deposition of a basecoat and clearcoat by a wet-on-wet process. Subsequently, baking is performed again. However, in recent years, car manufacturers have been required to reduce the environmental burden of their manufacturing processes, which mainly involves reducing carbon dioxide emissions [4]. Currently, the standard coating method is called 3-coat-1-bake (3C1B), in which the primer surfacer, basecoat, and clearcoat are applied by a wet-on-wet-on-wet process without baking the primer surfacer.

Coating and baking processes generate heterogeneous wavelengths on the coating film surface. Unfortunately, the extent of this waviness is larger in the $3 \mathrm{C} 1 \mathrm{~B}$ process than in the conventional 3-coat-2-bake painting, which degrades the appearance of the coating surface. Variety of methods have been proposed to resolve this problem, and many fundamental studies on automotive paint appearance have been performed. For example, Peters et al. evaluated texture evolution during the curing process [5]. Ellwood et al. have evaluated the effect of particle droplet size on the appearance of coating surface [6]. Domenico et al. have studied the effect of bell application parameters on the appearance of coating surface [7]. Osterhold et al. have characterized the surface structure of plastics coatings [8] 
and appearance of the surfaces [9]. Lin et al. have reviewed several factors that affect the appearance of coating surface and studied the effect of crosslinking chemistry on substrate telegraphing [10]. Recently, the authors suggested a 3C1B coating system by adopting base resins with a low glass transition temperature to promote levelling and by reducing the melamine content of the paint to minimize shrinkage during baking [11]. Then, Hayashi et al. developed a new $3 \mathrm{C} 1 \mathrm{~B}$ coating system with waviness equivalent to a conventional 3-coat-2-bake coating system for economy-class automobiles [12]. However, the authors seek novel concept of another $3 \mathrm{C} 1 \mathrm{~B}$ coating system which is applicable to luxury-class automobiles which coating appearance has less waviness than economy-class. Carbon dioxide emissions can be more reduced during painting if $3 \mathrm{C} 1 \mathrm{~B}$ coating system is applied to luxury-class automobiles, too. Therefore, car manufacturers also seek another $3 \mathrm{C} 1 \mathrm{~B}$ coating system which is environmentally friendly for the luxury-class automobiles.

In this study, we focused on the shrinkage during bake and examined whether the appearance is improved by reducing the difference in the shrinkage percentage between the primer surfacer and the basecoat and the clearcoat after flow/leveling stops in the clearcoat while baking. Figures 1 and 2 show a schematic representation of the telegraphing of interface waviness. Figure 1 shows that the shrinkage percentage is different between the upper and lower layers after flow/leveling stops in the upper layer, and Figure 2 shows that the shrinkage percentage is the same between the upper and lower layers after flow/leveling stops in the upper layer. Although Figure 1 shows that telegraphing occurs on the surface, Figure 2 shows that telegraphing does not occur. Thus, it is considered that the waviness of the interfaces does not correspond to the waviness of the surface. Consequently, if the difference in the shrinkage percentage can be reduced to nearly zero, the waviness of the interfaces will not be telegraphed or reduced, which minimizes the waviness of the surface. So far there is some literature provided that minimizing whole shrinkage percentage of multilayer coating films can improve appearance, but no literature or patent provided that minimizing shrinkage percentage difference between those layers also can improve appearance. In this study, we examined whether this consideration is correct.

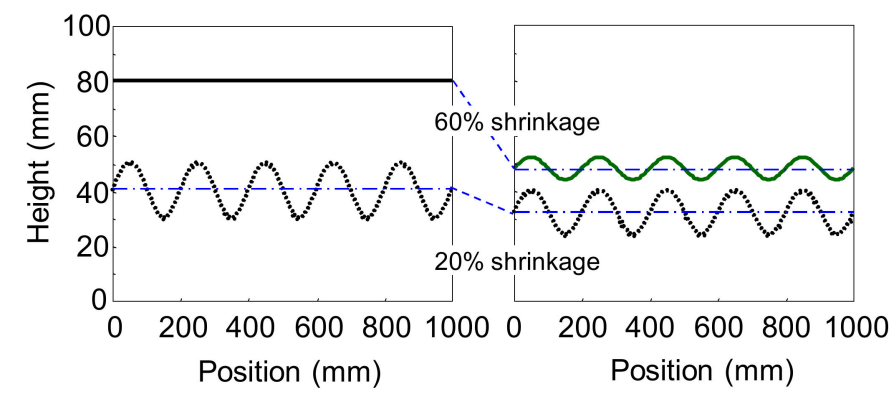

Figure 1. Schematic representation of telegraphing of interface waviness (shrinkage percentage between upper layer and lower layer is different).

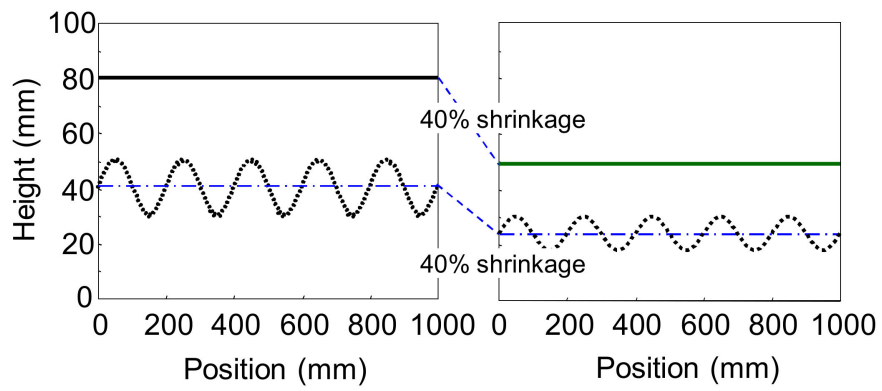

Figure 2. Schematic representation of telegraphing of interface waviness (shrinkage percentage between upper layer and lower layer is same). 
Based on the coating film, which consists of a melamine-curable primer surfacer, basecoat, and isocyanate-curable $2 \mathrm{~K}$-clearcoat, the shrinkage percentage after flow / leveling stops in the clearcoat follows basecoat $>$ primer surfacer $>$ clearcoat. This occurs because:

- The crosslinking reaction is faster for isocyanate than for melamine;

- Isocyanate crosslinking is an addition reaction, and melamine crosslinking is a condensation reaction.

- The amount of melamine resin follows basecoat $>$ primer surfacer. We examined the relationship between the appearance and melamine resin amount in the basecoat or blocking agent amount for isocyanate in the clearcoat.

\section{Materials and Methods}

\subsection{Materials}

Table 1 shows the compounds prepared in this study as follows: a melamine-curable waterborne primer surfacer, waterborne basecoats with different melamine resin contents, and solventborne clearcoats, in which the curing agent isocyanate was partially or completely blocked by 3,5-dimethylpyrazole (DMP). A waterborne primer surfacer with a $T_{g}$ of $20{ }^{\circ} \mathrm{C}$ was prepared by synthesizing the hydroxyl-containing acrylic resin AcEm-1 with the addition of Cymel 325 (melamine resin manufactured by Allnex, Frankfurt, Germany) as a curing agent, titanium dioxide (mixed with carbon black pigment) for pigment dispersion, an organic solvent, and other additives (Table 2). A waterborne basecoat with a $T_{g}$ of $20{ }^{\circ} \mathrm{C}$ was prepared by synthesizing the hydroxyl-containing acrylic resin AcEm-2 and adding Cymel 325, an aluminum flake disperser, an organic solvent, and other additives (Table 3). The solventborne clearcoat was obtained by synthesizing a hydroxyl-containing acrylic resin and using four types of isocyanate blockers (manufactured by blending polyisocyanate Duranate TPA-100 and DMP; Asahikasei Chemicals, Tokyo, Japan) (Table 4). After adding organic solvents and additives, four types of solventborne clearcoats were prepared (Table 5).

Table 1. Curing agents.

\begin{tabular}{cccc}
\hline \multirow{2}{*}{ Paint } & Name & $\begin{array}{c}\text { Curing Agent } \\
\text { Product }\end{array}$ & Amount (PHR) \\
\hline Primer Surfacer & WP & Cymel325 & 30 \\
& WB-1 & Cymel325 & 30 \\
\multirow{2}{*}{ Basecoat } & WB-2 & Cymel325 & 20 \\
& WB-3 & Cymel325 & 10 \\
& WB-4 & None & 35 \\
Clearcoat & SC-1 & DPA-100 blocked 0.25eq by DMP & 35 \\
& SC-2 & TPA-100 blocked 0.5eq by DMP & 35 \\
& SC-3 & TPA-100 blocked 1.0eq by DMP & 35 \\
\hline
\end{tabular}

PHR: Per Hundred Resin.

Table 2. Formulation of waterborne primer surfacer (wt.\%).

\begin{tabular}{cc}
\hline Material & WP \\
\hline AcEm-1 & 39.6 \\
Cymel325 & 7.4 \\
DIW & 5.9 \\
Organic solvent & 2.9 \\
Anti-popping agent & 0.5 \\
Rheology control agent & 1.6 \\
Neutralizer & 0.3 \\
Pigment dispersion & 41.8 \\
Total & 100.0 \\
\hline
\end{tabular}


Table 3. Formulation of waterborne basecoats (wt.\%).

\begin{tabular}{ccccc}
\hline Material & WB-1 & WB-2 & WB-3 & WB-4 \\
\hline AcEm-2 & 37.4 & 41.5 & 45.4 & 49.0 \\
Cymel325 & 6.9 & 4.5 & 2.2 & 0.0 \\
DIW & 33.1 & 32.1 & 31.2 & 30.3 \\
Organic solvent & 5.5 & 5.4 & 5.2 & 5.1 \\
Rheology control agent & 3.1 & 3.0 & 2.9 & 2.8 \\
Neutralizer & 0.4 & 0.4 & 0.3 & 0.3 \\
Defoaming agent & 1.1 & 1.1 & 1.1 & 1.1 \\
Aluminum flake disperser & 12.5 & 12.1 & 11.7 & 11.4 \\
Total & 100.0 & 100.0 & 100.0 & 100.0 \\
\hline
\end{tabular}

Table 4. Formulation of blocked isocyanate (wt.\%).

\begin{tabular}{cc}
\hline Material & Percentage \\
\hline Duranate TPA-100 & 49.1 \\
DMP & 26.4 \\
Organic solvent & 24.5 \\
Total & 100.0 \\
\hline
\end{tabular}

Table 5. Formulation of solventborne clearcoats (wt.\%).

\begin{tabular}{ccccc}
\hline Material & SC-1 & SC-2 & SC-3 & SC-4 \\
\hline Acrylic resin & 64.6 & 62.2 & 60.1 & 56.0 \\
Duranate TPA-100 & 14.9 & 10.8 & 6.9 & 0.0 \\
Blocked isocyanate & 0.0 & 7.3 & 14.0 & 26.2 \\
Organic solvent & 17.4 & 16.8 & 16.2 & 15.1 \\
UVA & 0.8 & 0.8 & 0.8 & 0.7 \\
HALS & 0.8 & 0.8 & 0.8 & 0.7 \\
Surface control agent & 0.6 & 0.6 & 0.6 & 0.5 \\
Anti-popping agent & 0.8 & 0.8 & 0.8 & 0.7 \\
Total & 100.0 & 100.0 & 100.0 & 100.0 \\
\hline
\end{tabular}

\subsection{Appearance Evaluation}

As a substrate, an electrodeposition-coated steel plate was prepared with a surface roughness (Ra) of 0.14 $\mu \mathrm{m}$ measured according to JIS B0601-2001 using a Surftest SJ-301 manufactured by Mitsutoyo (Kawasaki, Japan). A wet-on-wet-on-wet process was used for the application. The various combinations of waterborne primer surfacer, waterborne basecoat, and solventborne clearcoat on the substrate are shown in Table 6. Then, the sample was baked (horizontally) under the following conditions: 10-min flash-off followed by a 30 -min pass at $140{ }^{\circ} \mathrm{C}$. After baking, the wavescan values Wa (a digitized waviness with a wavelength of 0.1 to $0.3 \mathrm{~mm}$ ), Wb (0.3 to $1.0 \mathrm{~mm}$ ), Wc (1 to $3 \mathrm{~mm}$ ), and $\mathrm{Wd}$ (3 to $10 \mathrm{~mm}$ ) were measured at room temperature. Better appearance was obtained when the wavescan values were smaller. The coatings were applied using an air-spray handgun (W-71S: spray distance $=30 \mathrm{~cm}$; manufactured by Anest Iwata (Yokohama, Japan). After applying the waterborne primer surfacer, the sample was pre-heated with a 3-min flash-off and a 3-min pass at $80^{\circ} \mathrm{C}$. After applying the waterborne basecoat, the sample was further heated with a 1.5-min flash-off and a 3-min pass at $80^{\circ} \mathrm{C}$. The target film thicknesses of the primer surfacer, basecoat, and clearcoat were 20,15, and $35 \mu \mathrm{m}$, respectively. The wavescan values $\mathrm{Wa}, \mathrm{Wb}, \mathrm{Wc}$, and $\mathrm{Wd}$ were measured using a wavescan instrument manufactured by BYK-Gardner. The results are presented as the averages and standard deviations of three independent measurements. 
Table 6. Paint combinations and shrinkage percentages after $t_{C}$.

\begin{tabular}{|c|c|c|c|c|c|c|c|c|c|}
\hline \multirow{2}{*}{ No. } & \multicolumn{3}{|c|}{ Paint } & \multirow{2}{*}{$t_{C}(\mathrm{~s})$} & \multicolumn{5}{|c|}{ Shrinkage Percentage After $t_{C}(\%)$} \\
\hline & $\begin{array}{c}\text { Primer } \\
\text { Surfacer (S) }\end{array}$ & Basecoat (B) & Clearcoat (C) & & $\omega_{\mathrm{S}}$ & $\omega_{B}$ & $\omega_{C}$ & $\left|\omega_{S}-\omega_{B}\right|$ & $\left|\omega_{B}-\omega_{C}\right|$ \\
\hline 1 & WP & WB-1 & SC-1 & 270 & 2.5 & 4.2 & 0.8 & 1.7 & 3.4 \\
\hline 2 & WP & WB-2 & SC-1 & 270 & 2.5 & 3.2 & 0.8 & 0.7 & 2.4 \\
\hline 3 & WP & WB-3 & SC-1 & 270 & 2.5 & 1.9 & 0.8 & 0.6 & 1.1 \\
\hline 4 & WP & WB-4 & SC-1 & 270 & 2.5 & 1.3 & 0.8 & 1.2 & 0.5 \\
\hline 5 & WP & WB-1 & SC-2 & 310 & 2.3 & 4.0 & 2.5 & 1.7 & 1.5 \\
\hline 6 & WP & WB-1 & SC-3 & 370 & 2.0 & 3.3 & 6.5 & 1.3 & 3.2 \\
\hline 7 & WP & WB-1 & SC-4 & 450 & 1.4 & 2.0 & 7.9 & 0.6 & 5.9 \\
\hline
\end{tabular}

\subsection{Measurement of Flow/Leveling Stop Time in the Clearcoat}

The abovementioned clearcoat was applied to a stainless-steel plate $(40 \times 50 \times 0.5 \mathrm{~mm})$ using a bar coater. The target film thickness was $100 \mu \mathrm{m}$ after baking. Then, the sample was set in the electric-field tweezers system developed by Sakai Laboratory (Institute of Industrial Technology, University of Tokyo and manufactured by Kyoto Denshi Kogyo (Kyoto, Japan) (Figure 3) [13]. This system deforms the coating surface using an electric field and measures the viscosity from the recovery behavior. The measurement conditions were as follows: needle-to-surface distance $=100 \mu \mathrm{m}$; voltage $=5 \mathrm{~V}$; voltage $\mathrm{ON}$ time $=1.0 \mathrm{~s}$; and voltage $\mathrm{OFF}$ time $=1.0 \mathrm{~s}$. The voltage $\mathrm{ON}$ and $\mathrm{OFF}$ cycle was repeated. After the application of the clearcoat, the temperature was increased from $20^{\circ} \mathrm{C}$ to $140{ }^{\circ} \mathrm{C}$ in $20^{\circ} \mathrm{C} /$ minute steps and held at $140^{\circ} \mathrm{C}$ for $24 \mathrm{~min}$. While heating and maintaining the temperature, the position of the sample surface was detected by irradiating the surface with laser light and capturing the surface-reflected light with a photodetector. By converting the detected position into voltage, the level above and below the position of the sample surface was read as voltage fluctuation (Figure 4). The voltages were recorded at 0.01-s intervals. After completing the measurement, the fluctuation width $a$ of the detected voltage owing to the ON/OFF voltage was smoothed by the simple moving average method every 20 points (Figure 5). The time required to reach $5 \%$ of the maximum fluctuation width $a_{\max }$ was taken as the time that the flow/leveling stopped (abbreviated as $t_{C}$ ) (Figure 6). The measurement was performed with $\mathrm{n}=2$.

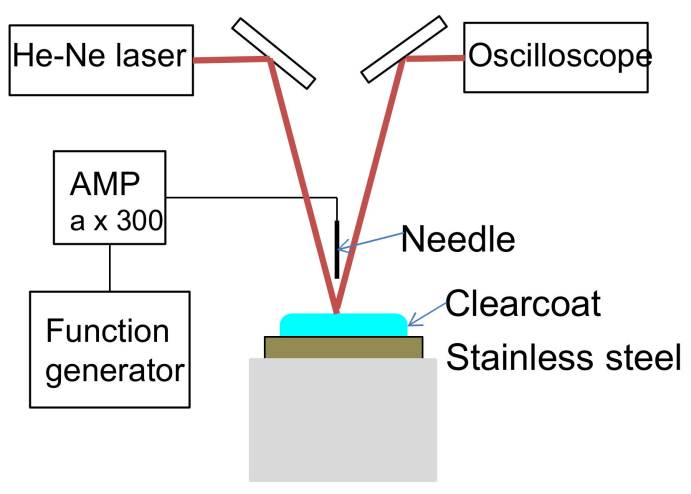

Figure 3. Electric-field tweezers system.

\subsection{Measurement of Shrinkage Rate $\omega$ after Flow/Leveling Stop in the Clearcoat}

The waterborne primer surfacer, waterborne basecoat, and solventborne clearcoat described above were air-sprayed on a weighed stainless-steel foil to form the film thicknesses after baking of 20,15 , and $35 \mu \mathrm{m}$ (booth temperature: $23{ }^{\circ} \mathrm{C} ; 68 \%$ relative humidity). Prior to baking, the film was pre-heated twice for $3 \mathrm{~min}$ at $80^{\circ} \mathrm{C}$ (only for the waterborne primer surfacer) and pre-heated once for $3 \mathrm{~min}$ at $80^{\circ} \mathrm{C}$ (only for the waterborne basecoat). Then, the film was baked for a pass equivalent to $t_{C}$ at $140{ }^{\circ} \mathrm{C}$. Then, the film was weighed 
and baked for a pass equivalent to further $\left(30-t_{C}\right)$ at $140{ }^{\circ} \mathrm{C}$, followed again by weighing. The shrinkage rate by weight $\omega$ was calculated using Equation (1). Each measurement was performed with $n=3 . \omega_{S}$ denotes the shrinkage percentage of the waterborne primer surfacer after $t_{C} ; \omega_{B}$ denotes the shrinkage percentage of the waterborne basecoat after $t_{C}$, and $\omega_{C}$ denotes the shrinkage percentage of the solventborne clearcoat after $t_{C}$ :

$$
\omega_{x}=100(Y-Z) /(Z-X) x=S, B, C
$$

where, $\omega_{x}$ is the shrinkage percentage after $t_{C}(\%), X$ is the weight of the stainless-steel foil (g), $Y$ is the weight of the stainless-steel foil and coating film (g) after baking for a pass equivalent to $t_{C}$ at $140{ }^{\circ} \mathrm{C}$, and $\mathrm{Z}$ is the weight of the stainless-steel foil and coating film (g) after baking for a 30 -min pass at $140^{\circ} \mathrm{C}$.

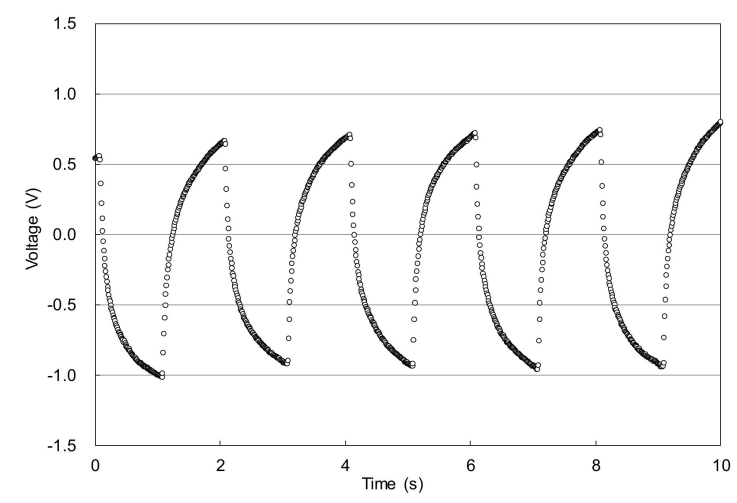

Figure 4. Example of time dependence of detected voltage.

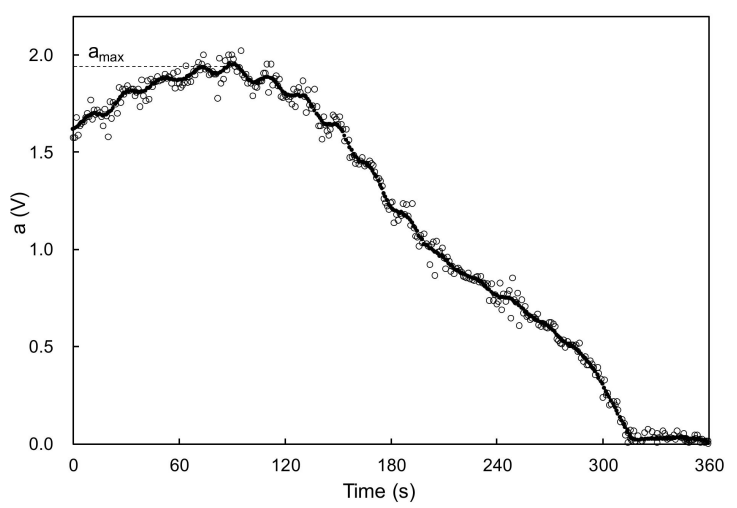

Figure 5. Example of time dependence of fluctuation width a and determination of $a_{\max }$.

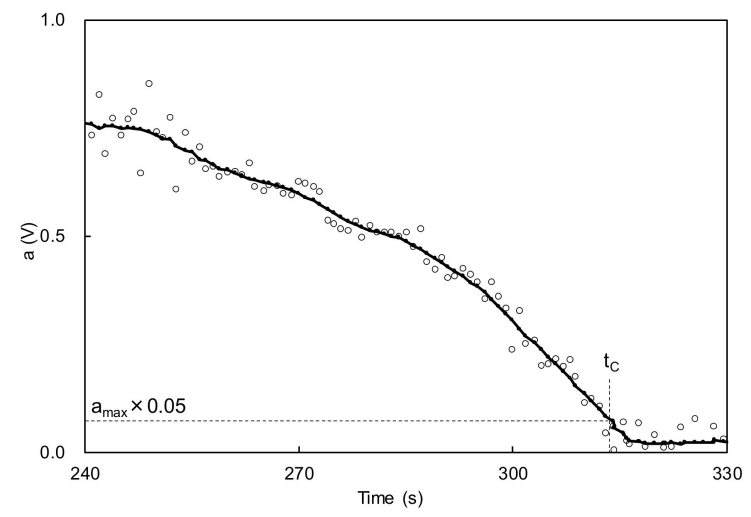

Figure 6. Example of time dependence of fluctuation width a (expansion of Figure 5) and determination of $t_{C}$. 


\subsection{Measurement of Viscosity}

The viscosities of waterborne basecoat and solventborne clearcoat were measured while increasing the shear rate from $10^{-1}$ to $10^{3} \mathrm{~s}^{-1}$. Measurements were performed using an ARES-G2 rheometer (TA Instruments, New Castle, DE, USA) at $25.0 \pm 0.1^{\circ} \mathrm{C}$. The geometry of the solventborne clearcoat samples was set by a 25 -mm-diameter cone plate (angle $=0.04 \mathrm{rad}$ ). The gap was set to $50 \mu \mathrm{m}$.

\section{Results and Discussion}

\subsection{Relationship Between $t_{C}$ and $\omega$}

In the solventborne clearcoat, $t_{C}$ increased with an increase in the amount of DMP (Figure 7). This can be explained by the negligible viscosity increase. Clearly, the crosslinking reaction proceeds only above a certain temperature threshold even when DMP blocking increases the temperature. Figure 8 shows $\omega_{S}, \omega_{B}$, and $\omega_{C}$ versus $t_{C}$ from Table 6 , when the amounts of waterborne primer surfacer and waterborne basecoat were fixed and the DMP content of the solventborne clearcoat was varied (combinations 1, 5, 6, and 7 in Table 6). Both $\omega_{S}$ and $\omega_{B}$ decreased with an increase in $t_{C}$; however, $\omega_{C}$ increased under the same condition. This is attributed to the volatilization of DMP after the flow/leveling stop in the clearcoat.

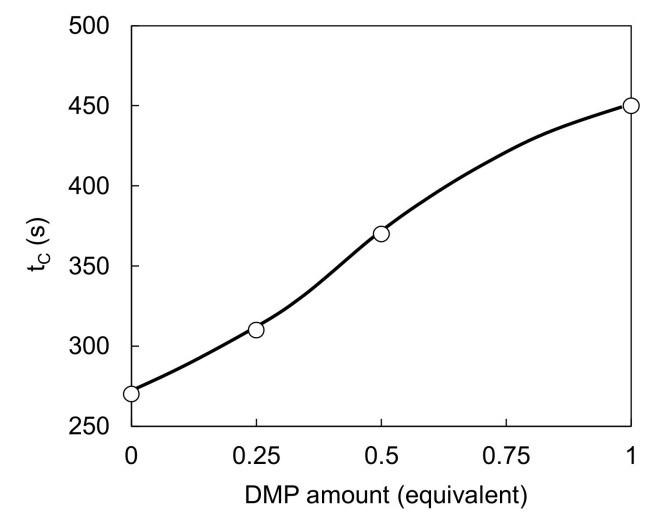

Figure 7. Relationship between DMP amount and $t_{C}$

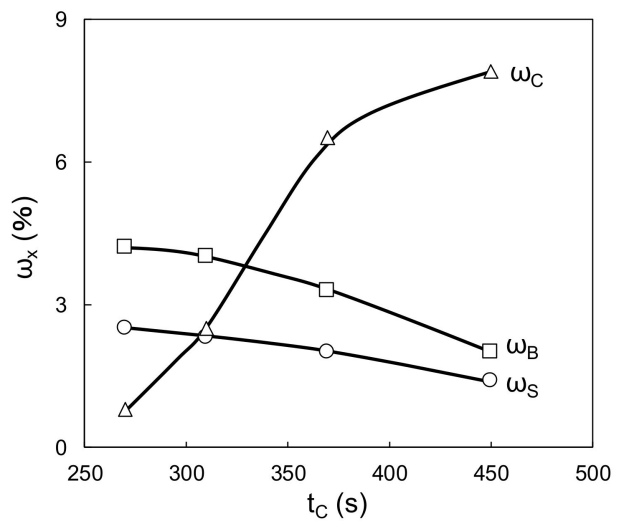

Figure 8. Relationship between $t_{C}$ and $\omega\left(\omega_{S}\right.$; primer surfacer, $\omega_{B}$; basecoat; $\omega_{C}$; clearcoat).

\subsection{Appearance Improvement by Reduction of Melamine Resin in the Basecoat}

Table 6 shows the $\omega$ and shrinkage percentage differences in each combination. $\omega_{B}$ decreased as the melamine resin content decreased. This occurs because the amounts of volatile compounds (e.g., alcohols by condensation reaction between acrylic and melamine resins) decreased. Whereas $\left|\omega_{S}-\omega_{B}\right|$ decreased and then increased as the melamine resin content increased. $\left|\omega_{B}-\omega_{C}\right|$ decreased as the amount of melamine resin decreased. 
Figures 9 and 10 show the relationships between the four wavescan values and $\left|\omega_{S}-\omega_{B}\right|$ and $\left|\omega_{B}-\omega_{C}\right|$, respectively. Wa, $\mathrm{Wb}, \mathrm{Wc}$, and $\mathrm{Wd}$ fluctuated as $\left|\omega_{S}-\omega_{B}\right|$ increased, and monotonically increased as $\left|\omega_{B}-\omega_{C}\right|$ increased. Furthermore, given that the viscosity of the waterborne basecoat under a high shear rate $\left(10^{4} \cdot \mathrm{s}^{-1}\right)$ barely changed in response to the melamine resin content (calculated by extrapolating from viscosities of $630 \mathrm{~s}^{-1}$ and $1000 \mathrm{~s}^{-1}$, see Figure 11), the atomization state at the time of spraying is unlikely to depend on the samples. Then, $\mathrm{Wa}, \mathrm{Wb}, \mathrm{Wc}$, and $\mathrm{Wd}$ tend to increase when $\left|\omega_{S}-\omega_{B}\right|+\left|\omega_{B}-\omega_{C}\right|$ increases (Figure 12). These results suggest that the surface waviness of the clearcoat is governed by the different shrinkage percentages between the layers after the flow/leveling stops in the clearcoat. We noted that reduction of melamine resin in the basecoat can reduce volatile organic compounds during baking coating film.

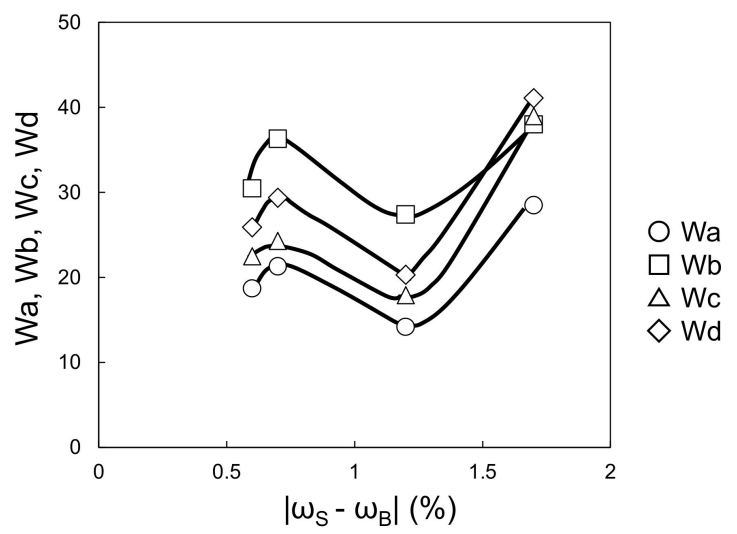

Figure 9. Relationship between $\left|\omega_{S}-\omega_{B}\right|$ and Wa-Wd (changing melamine resin content in waterborne basecoat).

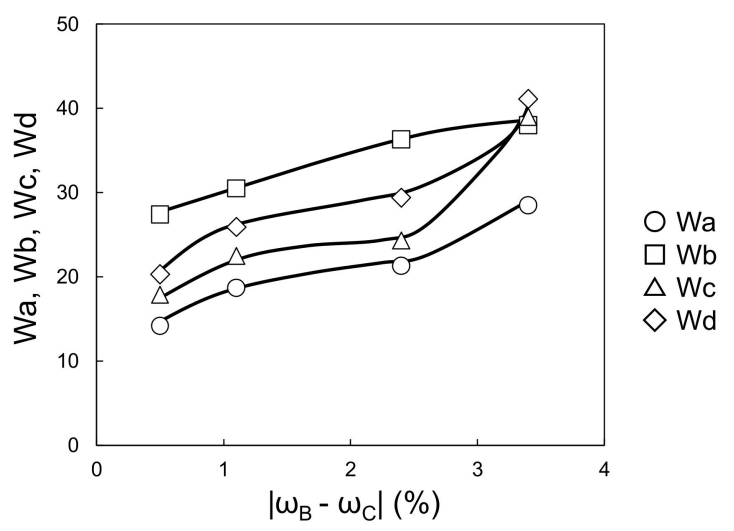

Figure 10. Relationship between $\left|\omega_{B}-\omega_{C}\right|$ and Wa-Wd (changing melamine resin content in waterborne basecoat).

\subsection{Appearance Improvement by the Addition of DMP into the Clearcoat}

Table 6 shows $\left|\omega_{S}-\omega_{B}\right|,\left|\omega_{B}-\omega_{C}\right|$. The $\omega_{B}$ value decreased as $t_{C}$ increased, and $\omega_{C}$ increased as the amount of blocking agent increased. Consequently, $\left|\omega_{S}-\omega_{B}\right|$ decreased when DMP increased, and $\left|\omega_{B}-\omega_{C}\right|$ is equivalent to blocking agent amounts of $0.25<0<0.5<1.0$. Figure 13 shows that $\mathrm{Wa}, \mathrm{Wb}, \mathrm{Wc}_{\mathrm{c}}$, and $\mathrm{Wd}$ increased when $\left|\omega_{S}-\omega_{B}\right|+\left|\omega_{B}-\omega_{C}\right|$ increased. This suggests that in this coating system, the surface appearance is predominantly governed by the shrinkage differences at the interfaces. Figure 14 shows an actual image of the surface of the coatings.

The abovementioned results confirm that if $\omega$ is obtained through the accurate measurement of the flow/leveling stops, then appearance can be related to the shrinkage percentage between the paint layers even in systems containing different types of clearcoats. Table 7 lists $\mathrm{Wa}, \mathrm{Wb}, \mathrm{Wc}$, and $\mathrm{Wd}$. 


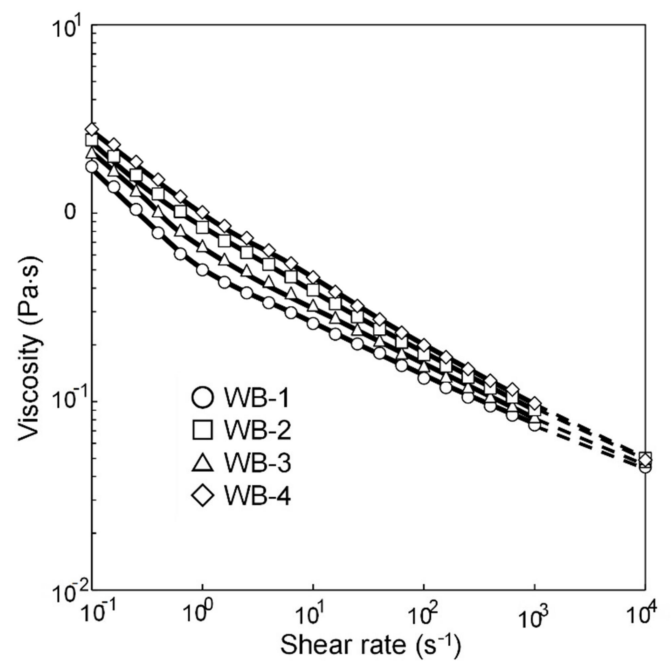

Figure 11. Shear rate dependence of viscosity of waterborne basecoats.

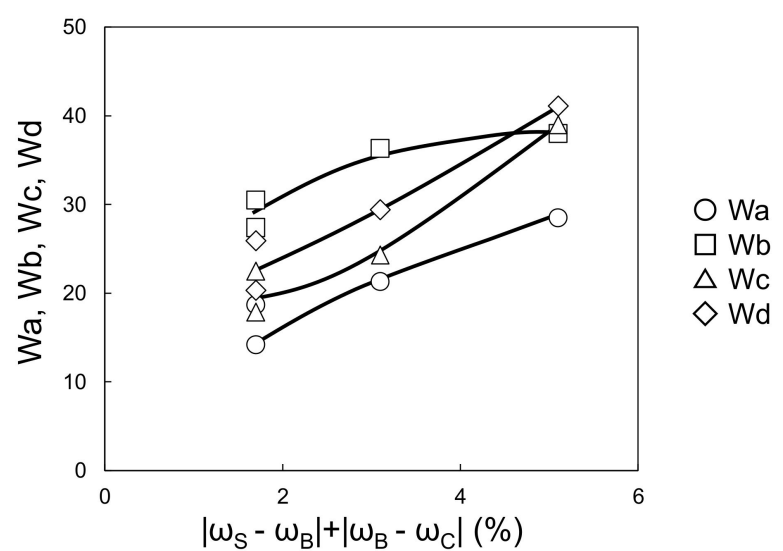

Figure 12. Relationship between $\left|\omega_{S}-\omega_{B}\right|+\left|\omega_{B}-\omega_{C}\right|$ and Wa-Wd (changing melamine resin content in waterborne basecoat).

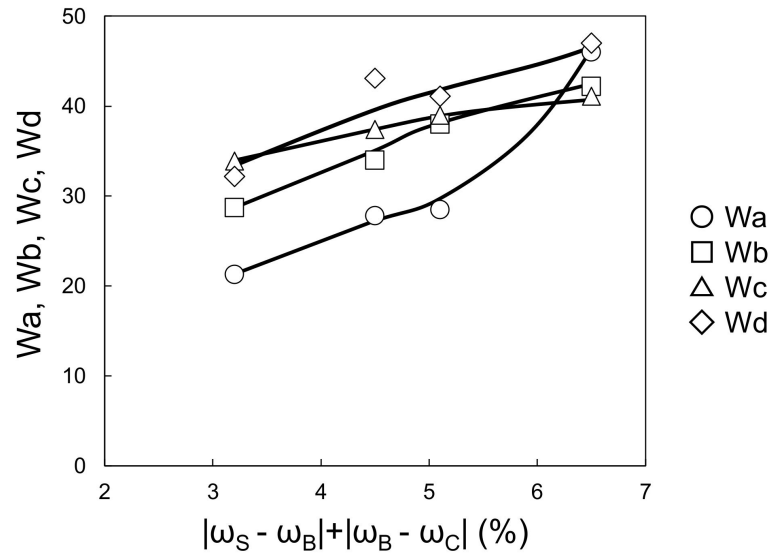

Figure 13. Relationship between $\left|\omega_{S}-\omega_{B}\right|+\left|\omega_{B}-\omega_{C}\right|$ and Wa-Wd (changing DMP content in solventborne clearcoat).

Surface waviness is affected by the atomization and leveling of the clearcoat. The viscosity was assumed to be almost independent of the DMP content of the clearcoat. However, after determining the viscosity behavior, the role of viscosity in the relationship 
between clearcoat atomization and surface appearance was reconsidered. The amount of blocking agent, $0.25<0.5<0<1.0$, is equivalent to $\left|\omega_{B}-\omega_{C}\right|$. If atomization and leveling of the clearcoat markedly reduce $\mathrm{Wa}, \mathrm{Wb}, \mathrm{Wc}$, and $\mathrm{Wd}$, the viscosity at the high shear rate $\left(10^{4} \mathrm{~s}^{-1}\right)$ of the clearcoat (calculated by extrapolating viscosities of $630 \mathrm{~s}^{-1}$ and $1000 \mathrm{~s}^{-1}$ ) can be considered to be equivalent to the blocking agent amount of $0.25<0.5<0<1.0$. However, the viscosity was equivalent to the blocking agent amounts of $1.0<0<0.25<0.5$ (Figure 15) and did not correlate with $\mathrm{Wa}, \mathrm{Wb}, \mathrm{Wc}$, and $\mathrm{Wd}$. Thus, in this coating system, the atomization of the clearcoat had only a small effect on the surface appearance.

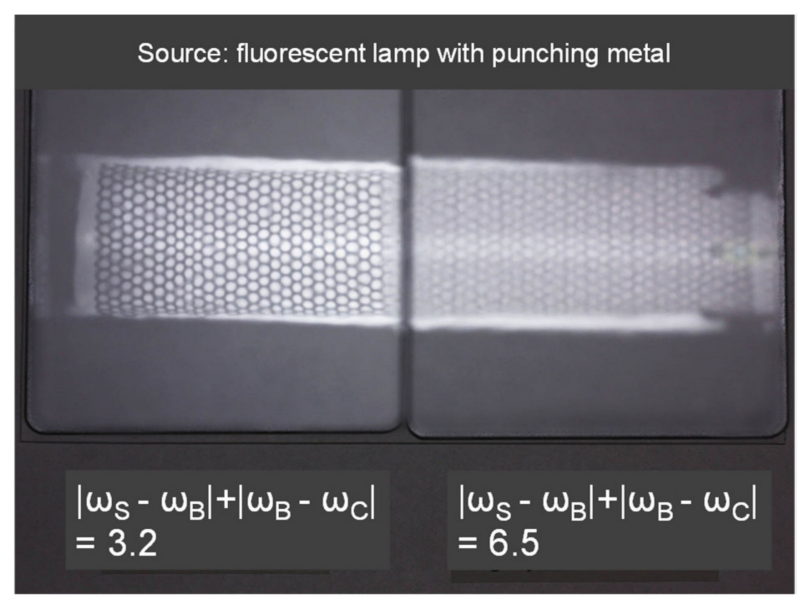

Figure 14. Image of coating surface of two panels (left; $\left|\omega_{S}-\omega_{B}\right|+\left|\omega_{B}-\omega_{C}\right|=3.2$, right; $\left|\omega_{\mathrm{S}}-\omega_{\mathrm{B}}\right|+\left|\omega_{\mathrm{B}}-\omega_{\mathrm{C}}\right|=6.5$, source; fluorescent lamp with punching metal).

Table 7. Wavescan values obtained by changing basecoat and clearcoat.

\begin{tabular}{cccccccc}
\hline \multirow{2}{*}{ No. } & $\begin{array}{c}\text { Primer } \\
\text { Surfacer }\end{array}$ & Basecoat & Clearcoat & \multicolumn{4}{c}{ Wavescan Values } \\
& & & & Wa & Wb & Wc & Wd \\
\hline 1 & WP & WB-1 & SC-1 & $28.5 \pm 2.3$ & $38.0 \pm 2.1$ & $39.0 \pm 1.3$ & $41.1 \pm 1.5$ \\
2 & WP & WB-2 & SC-1 & $21.3 \pm 1.3$ & $36.3 \pm 2.1$ & $24.3 \pm 1.1$ & $29.4 \pm 2.1$ \\
3 & WP & WB-3 & SC-1 & $18.7 \pm 1.1$ & $30.5 \pm 2.3$ & $22.5 \pm 1.5$ & $25.9 \pm 1.3$ \\
4 & WP & WB-4 & SC-1 & $14.2 \pm 1.5$ & $27.4 \pm 1.9$ & $17.9 \pm 1.1$ & $20.3 \pm 1.8$ \\
5 & WP & WB-1 & SC-2 & $21.3 \pm 1.4$ & $31.7 \pm 1.7$ & $33.9 \pm 1.4$ & $32.2 \pm 2.0$ \\
6 & WP & WB-1 & SC-3 & $27.8 \pm 1.5$ & $34.0 \pm 1.5$ & $37.4 \pm 1.8$ & $43.1 \pm 1.9$ \\
7 & WP & WB-1 & SC-4 & $46.0 \pm 2.4$ & $41.1 \pm 1.7$ & $41.1 \pm 1.7$ & $47.0 \pm 1.4$ \\
\hline
\end{tabular}

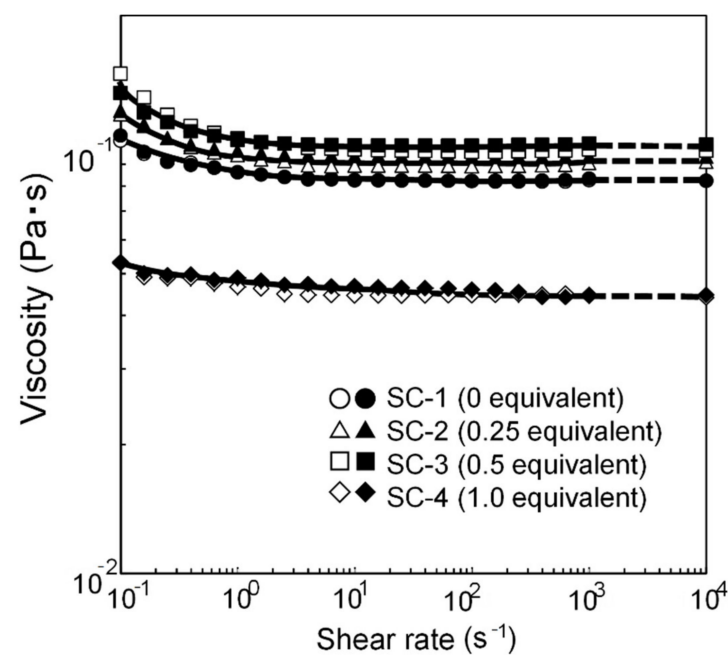

Figure 15. Shear rate dependence of viscosity of solventborne clearcoats. 
We noted that increasing of DMP as blocking agent in the clearcoat can increase volatile organic compounds during baking coating film.

\section{Conclusions}

This study examined whether the surface appearance of a $3 \mathrm{C} 1 \mathrm{~B}$ coating system can be effectively improved by reducing the shrinkage percentage difference between the primer surfacer/basecoat layer and between the basecoat/clearcoat layer after flow/leveling stops in the clearcoat layer.

- This shrinkage percentage difference was reduced by decreasing the shrinkage percentage of the basecoat by reducing melamine resin content in the basecoat. $\mathrm{Wa}, \mathrm{Wb}$, $\mathrm{Wc}$, and Wd started to decrease when the shrinkage percentage difference between the primer surfacer and the basecoat plus between the basecoat and the clearcoat layers decreased.

- Also, the shrinkage percentage difference was reduced by increasing the shrinkage percentage of the clearcoat by mixing DMP into an isocyanate-curable solventborne clearcoat. At $t=t_{C}$ (measured using the electric-field tweezers system), the wavescan values $\mathrm{Wa}, \mathrm{Wb}, \mathrm{Wc}$, and $\mathrm{Wd}$ started to decrease when the shrinkage percentage difference between those layers decreased.

These results demonstrate that the shrinkage percentage difference between the layers after the flow /leveling stops in the clearcoat layer can be reduced by controlling the time to $t_{C}$ (by mixing DMP into the clearcoat), which leads to an improvement in appearance.

Author Contributions: Conceptualization, S.Y. and K.T.; methodology, S.Y. and K.T.; writingoriginal draft preparation, S.Y.; writing-review and editing, S.Y.; All authors have read and agreed to the published version of the manuscript.

Funding: This research received no external funding.

Data Availability Statement: No new data were created or analyzed in this study. Data sharing is not applicable to this article.

Acknowledgments: The authors would like to express their sincere gratitude to Hiroshi Nakamura and Masahiko Ishii of the Toyota Central R \& D Labs, Inc. for their useful discussions and guidance in preparing this manuscript.

Conflicts of Interest: The authors declare no conflict of interest.

\section{References}

1. Fotovvati, B.; Namdari, N.; Dehghanghadikolaei, A. On coating techniques for surface protection: A review. J. Manuf. Mater. Process. 2019, 3, 28. [CrossRef]

2. Chelu, M.; Stroescu, H.; Anastasescu, M.; Calderon-Moreno, J.M.; Preda, S.; Stoica, M.; Fogarassy, Z.; Petrik, P.; Gheorghe, M.; Parvulescu, C. High-quality PMMA/ZnO NWs piezoelectric coating on rigid and flexible metallic substrates. Appl. Surf. Sci. 2020, 529, 147135. [CrossRef]

3. Ibrahim, H.; Dehghanghadikolaei, A.; Advincula, R.; Dean, D.; Luo, A.; Elahinia, M. Ceramic coating for delayed degradation of Mg-1.2 Zn-0.5 Ca-0.5 Mn bone fixation and instrumentation. Thin Solid Films 2019, 687, 137456. [CrossRef]

4. Shibata, H.; Iida, T.; Nasu, Y. Concept and topics of automotive production process for paint shop. J. Jpn. Surf. Finish. 2018, 69, 290. [CrossRef]

5. Peters, C.A.; Nichols, M.E.; Ellwood, K.R. The evolution of surface texture in automotive coatings. J. Coat. Technol. Res. 2011, 8, 469-480. [CrossRef]

6. Ellwood, K.R.; Tardiff, J.L.; Alaie, S.M. A simplified analysis method for correlating rotary atomizer performance on droplet size and coating appearance. J. Coat. Technol. Res. 2014, 11, 303. [CrossRef]

7. Di Domenico, J.; Henshaw, P. The effects of basecoat bell application parameters on elements of appearance for an automotive coatings process. J. Coat. Technol. Res. 2012, 9, 675. [CrossRef]

8. Osterhold, M.; Armbruster, K. Characterizing the surface structure of plastics coatings. Prog. Org. Coat. 2006, 165, 2006. [CrossRef]

9. Osterhold, M.; Armbruster, K. Characterizing the appearance of medium glossy surfaces. Prog. Org. Coat. 2009, 440, 2009. [CrossRef]

10. Lin, J.L.; Shen, J.; Zimmer, M.E. Appearance of Automotive Coatings. In Protective Coatings; Springer: Cham, Switzerland, 2017; Volume 377. [CrossRef] 
11. Yomo, S.; Tachi, K.; Narita, T. Improving the appearance of 3-coat-1-bake multilayer films on automotive bodies. Prog. Org. Coat. 2018, 299, 2018. [CrossRef]

12. Hayashi, H.; Ishii, M. SAE Technical Paper, No. 2014-01-1048; SAE International: Warrendale, PA, USA, 2014.

13. Sakai, K.; Yamamoto, Y. Electric field tweezers for characterization of liquid surface. Appl. Phys. Lett. 2006, $211911,2006$. [CrossRef] 